\title{
Studi Kepuasan Kerja untuk Pekerja Konstruksi Lulusan Baru di Indonesia
}

\author{
Moh Nur Sholeh ${ }^{1, *}$, Undayani Cita Sari ${ }^{2}$ \\ ${ }^{1}$ Departemen Sipil dan Perencanaan, Universitas Diponegoro, Semarang \\ ${ }^{2}$ Departemen Teknik Sipil, Universitas Diponegoro, Semarang \\ Koresponden*, Email: mohnursholeh@live.undip.ac.id
}

\begin{tabular}{lcl}
\hline & Info Artikel & Abstract \\
\hline Diajukan & 13 Nopember 2018 & Fresh graduate construction workers or millennial generation are currently increasingly \\
Diperbaiki & 10 Januari 2019 & dominating the construction company human resources. Potential fresh graduates also have \\
Disetujui & 1 Maret 2019 & $\begin{array}{l}\text { many challenges to manage. As a large number of new human resources, a study is needed on } \\
\text { how their performance and job satisfaction are. This study focuses on reviewing the } \\
\text { performance satisfaction of fresh graduate construction workers from their own perspective } \\
\text { by adopting several indicators from The Toyota Way. Calculation analysis method by ranking } \\
\text { the results of multiplication between the scale of application and individual development \& } \\
\text { teamwork. The results of the study show that the most satisfied indicator according to } \\
\text { construction workers fresh graduates is that leaders must have in-depth work knowledge with } \\
\text { a score of 18,574, while the satisfaction indicators that are most dissatisfied are training } \\
\text { material standardized with a score of 13,468. Future recommendations need innovation in } \\
\text { leadership style from the leaders of construction companies. }\end{array}$
\end{tabular}

\begin{abstract}
Abstrak
Pekerja konstruksi fresh graduate atau generasi milenial saat ini semakin mendominasi sumber daya manusia perusahaan konstruksi. Fresh graduate yang sangat potensial juga memiliki banyak tantangan untuk dikelola. Sebagai sumber daya manusia baru dengan jumlah banyak, sangat diperlukan kajian tentang bagaimana kinerja dan kepuasan kerja mereka. Penelitian ini fokus pada kajian kepuasan kinerja pekerja konstruksi fresh graduate dari sudut pandang mereka sendiri dengan mengadopsi beberapa indikator dari The Toyota Way. Metode analisa perhitungan dilakukan dengan merangking hasil perhitungan antara skala penerapan dan pengembangan individu \& teamwork. Hasil penelitian menunjukkan bahwa indikator yang paling memuaskan yang dirasakan oleh pekerja konstruksi fresh graduate adalah pemimpin harus memiliki pengetahuan kerja yang mendalam dengan skor 18.574, sedangkan indikator kepuasan yang menunjukkan ketidakpuasan adalah materi pelatihan dibakukan dengan skor 13.468. Selanjutnya, sebagai rekomendasi adalah perlu adanya inovasi gaya kepemimpinan dari para pemimpin perusahaan konstruksi.
\end{abstract}

Kata kunci: kepuasan kerja, fresh graduate,

pekerja konstruksi

\section{Pendahuluan}

Persaingan industri konstruksi di Indonesia semakin ketat seiring dengan banyaknya jumlah kontraktor dan pihak-pihak yang terkait dengan konstruksi. Menurut data Badan Pusat Statistik [1], jumlah perusahaan konstruksi di Indonesia berjumlah 142.852 yang didominasi oleh perusahaan skala kecil dan menengah daripada skala besar. Jumlah ini meningkat 6.58\% dari tahun 2015 ke 2016. Sedangkan jumlah pekerja tetapnya sebesar 979.772 orang, meningkat 1.69 dari tahun 2015 ke 2016. Ketatnya persaingan konstruksi membuat pelaku konstruksi harus bisa mengelola sumber daya perusahaan di setiap fase project life cycle. Hal ini dikarenakan pada fase ide, perencanaan, konstruksi/ pelaksanaan, dan operasi/pemeliharaan selalu ada waste yang perlu dikelola dan diminimalisir, salah satunya adalah waste sumber daya manusia [2]. Penelitian sebelumnya telah mengidentifikasi karakteristik tenaga kerja konstruksi yang

http://dx.doi.org/10.12962/j2579-891X.v17i1.4492 meliputi variasi keterampilan dengan sertifikat keahlian, identitas tugas, signifikansi tugas, dan komitmen kerja yang lebih berat di lapangan $[3,4]$.

Ritme kerja di pekerjaan konstruksi memang cukup berat dibandingkan sektor lainnya. Kinerja tenaga kerja di perusahaan konstruksi salah satunya dipengaruhi oleh motivasi kerja. Motivasi kerja yang dinginkan oleh pekerja pada penelitian sebelumnya terdiri dari gaji yang cukup, gaji tambahan, gaji tepat waktu, dukungan keluarga, dan ada upah lembur [5]. Selain gaji yang sesuai, kepuasan kinerja juga dipengaruhi oleh gaya kepemimpinan yang dapat meningkatkan moral pekerja [6]. Sebagai contoh, penelitian mengenai kinerja pekerja jasa konstruksi di Denpasar, menyatakan motivasi kerja dipengaruhi oleh kompensasi dan gaya kepemimpinan sebesar 7.64\% [7].

Saat ini generasi tenaga kerja baru di Indonesia didominasi oleh generasi milenial yang jumlahnya semakin banyak. 
Generasi milenial adalah generasi yang lahir tahun 19801995 atau yang serig disebut juga dengan Generasi Gen Y. Gaya kerja dan sudut pandang dalam melihat pekerjaan jika dibandingkan dengan generasi sebelumnya sedikit banyak berbeda. Penelitian mengenai adaptasi teori dan praktek kepemimpinan telah diterapkan pada generasi milenial yang merekomendasikan adanya kolaborasi antar pekerja [8]. Pandangan para pekerja secara umum juga menyampaikan kepuasan pekerja baru adalah promosi, pengawasan yang baik, rekan kerja, kompensasi, dan pekerjaan [9]. Sebagai contoh lainnya, kepuasan kinerja para pekerja baru atau fresh graduate di rumah sakit Amerika Serikat saat ini lebih cenderung ke tindakan kolektif, dengan optimisme masa depan, dan kepercayaan pada otoritas terpusat, menyukai kerja tim, menunjukkan keinginan yang kuat untuk menyelesaikan sesuatu dengan semangat yang luar biasa [10].

Meskipun memiliki semangat yang tinggi dalam bekerja dan berkolaborasi, generasi baru pekerja fresh gradate juga memiliki kelemahan diantaranya individualis, mudah bosan, ego sentris, ingin tampil beda, dan tidak sabar [11]. Penelitian di enam provinsi di Jawa Tengah menyatakan pekerja fresh graduate cenderung menginginkan gaji yang besar tanpa melihat terlebih dahulu bagaimana kinerja mereka [12]. Hal ini menjadi tantangan yang perlu diarahkan karena potensi fresh graduate dari generasi milenial ini sangat besar meskipun dengan beberapa kelemahannya. Sektor konstruksi sebagai industri yang fragmented dan penuh tantangan perlu dikaji bagaimana tingkat kepuasan kerja pekerjanya. Penelitian ini mengarah kepada para pekerja konstruksi baru sebagai generasi milenial yang merasakan bagaimana bekerja di dunia konstruksi dalam lima tahun terakhir.

\section{Metode}

Penelitian yang bertujuan mengkaji kepuasan pekerja fresh graduate konstruksi di Indonesia ini menggunakan indikator yang diadopsi dari lean construction management yang diserap dari konsep The Toyota Way. Lean construction merupakan cara baru untuk mengatur konstruksi dengan tujuan menuju konstruksi ramping, dimana diambil dari konsep lean production pada sistem manufaktur berdasarkan konsep Toyota Production System yang diadopsi pada bidang industri konstruksi [13]. Data kepuasan kinerja para pekerja konstruksi didapatkan dari kuesioner. Adapun indikator-indikator kepuasan kinerja yang diadopsi dari The Toyota Way dibagi menjadi dua kelompok besar yaitu kepemimpinan dan pengembangan individu \& teamwork. Masing-masing kelompok terdiri dari beberapa indikator, yang dapat dilihat pada Tabel 1.

Tabel 1. Indikator Kepuasan Kinerja Fresh Graduate Diadopsi dari The Toyota Way [14]

\begin{tabular}{|c|c|}
\hline Indikator & Kode \\
\hline \multicolumn{2}{|l|}{ Kepemimpinan } \\
\hline Pemimpin termotivasi untuk menginspirasi orang dalam mencapai tujuan & A1 \\
\hline Pemimpin harus memiliki pengetahuan kerja yang mendalam & A2 \\
\hline Pemimpin memiliki kemampuan mengajar dan mampu menyampaikan pengetahuan mereka kepada orang lain & A3 \\
\hline Pemimpin harus mendukung pekerja melakukan pekerjaan mereka & A4 \\
\hline Pemimpin akan membutuhkan waktu untuk memahami masalah dan akar penyebab sebelum bertindak & A5 \\
\hline Pemimpin mendorong pekerja untuk mengembangkan "continues improvement" dalam berpikir dan bertindak & A6 \\
\hline Pemimpin harus memahami kebijakan dan prosedur perusahaan, dan mengkomunikasikannya ke anggota tim & A7 \\
\hline \multicolumn{2}{|l|}{ Pengembangan Individu \& Teamwork } \\
\hline Pilih orang terbaik untuk pekerjaan tertentu & B1 \\
\hline $\begin{array}{l}\text { Pelatihan diberikan untuk melengkapi pekerja dengan keterampilan yang dibutuhkan sebelum mereka } \\
\text { ditugaskan untuk bekerja }\end{array}$ & B2 \\
\hline Pelatihan di tempat kerja disediakan untuk mengembangkan keterampilan luar biasa pekerja & B3 \\
\hline Materi pelatihan dibakukan & B4 \\
\hline Pekerja didorong untuk bekerja sama dengan orang lain untuk menyelesaikan seluruh tugas & B5 \\
\hline Aktivitas kerja harian diatur ke dalam fungsi tim & B6 \\
\hline Metode motivasi internal (kondisi kerja yang aman, gaji yang baik, rotasi pekerjaan) untuk memotivasi pekerja & B7 \\
\hline Metode motivasi eksternal (penghargaan, pujian, dan pengukuran terhadap tujuan) untuk memotivasi pekerja & B8 \\
\hline
\end{tabular}

Indikator-indikator pada Tabel 1 menjadi bahan kuesioner yang nantinya diisi oleh pekerja konstruksi fresh graduate sebagai responden. Target responden adalah mereka yang telah bekerja di perusahaan konstruksi baik pemerintah/kementerian PUPR, BUMN, dan swasta dalam 
waktu lima tahun terakhir. Sebagai batasan, fresh graduate pada penelitian ini adalah generasi milenial yang lulus dari Perguruan Tinggi pada tahun 2013-2018. Responden mengisi kuesioner berdasarkan pengalaman mereka terhadap indikator dari aspek kepemimpinan dan pengembangan individu \& teamwork.

Untuk memudahkan pandangan responden secara kualitatif, maka masing-masing indikator pada kuesioner dibuat secara kuantitatif berdasarkan aspek penerapan dan tingkat kepentingan dengan skala Likert 1-5 seperti pada Tabel 2-3. Skala aspek penerapan digunakan untuk mengetahui sejauh mana indikator diterapkan oleh pemimpin kepada pekerja fresh graduate. Sedangkan, Skala aspek tingkat kepentingan untuk mengetahui sejauh mana tingkat urgensi dari indikator tersebut.

Tabel 2. Skala Aspek Penerapan

\begin{tabular}{cl}
\hline Skala & \multicolumn{1}{c}{ Keterangan } \\
\hline 1 & Sangat tidak \\
2 & Sedikit \\
3 & Kadang-kadang \\
4 & Terjadi \\
5 & Sangat terjadi \\
\hline
\end{tabular}

Tabel 3. Skala Aspek Tingkat Kepentingan

\begin{tabular}{cl}
\hline Skala & \multicolumn{1}{c}{ Keterangan } \\
\hline 1 & Sangat tidak penting \\
2 & Tidak penting \\
3 & Biasa \\
4 & Penting \\
5 & Sangat penting \\
\hline
\end{tabular}

Kuesioner yang telah diisi responden kemudian diolah menggunakan perhitungan matematika untuk melihat dan menganalisa bagaimana pendapat para responden terhadap indikator yang ada. Tujuan dari perhitungan ini adalah membuat pandangan responden yang kualitatif menjadi kuantitatif, sehingga dapat dianalisa untuk kemudian diperoleh kesimpulan. Langkah-langkah analisa perhitungan adalah sebagai berikut.
a. Menghitung rata-rata nilai hasil pendapat responden da- ri skala aspek penerapan dan skala aspek tingkat kepen- tingan.
b. Mengalikan nilai aspek penerapan dan tingkat kepen- tingan dari masing-masing indikator.
c. Melakukan perangkingan indikator sesuai hasil perka- lian.

d. Membuat grafik dalam bentuk radar chart baik secara keseluruhan maupun dipisah antara aspek kepemimpinan dan pengembangan individu \& teamwork.

\section{Hasil dan Pembahasan}

Kuesioner yang telah dirancang kemudian didistribusikan ke semua pekerja konstruksi fresh graduate di seluruh Indonesia. Masa penyebaran kuesioner selama satu bulan. Hasilnya didapatkan jumlah responden yang mengisi kuesioner sebanyak 90 orang yang terpetakan seperti terlihat pada Tabel 4 .

Tabel 4. Komposisi Responden Berdasarkan Jenis Kelamin, Pendidikan, dan Skala Perusahaan

\begin{tabular}{llcc}
\hline \multicolumn{1}{c}{ Kriteria } & Sub Kriteria & $\begin{array}{c}\text { Jumlah } \\
\text { (orang) }\end{array}$ & \% \\
\hline Jenis kelamin & Laki-laki & 57 & 63.33 \\
& Perempuan & 33 & 36.67 \\
Tingkat pendidikan & DIII & 9 & 10.00 \\
& DIV/S1 & 78 & 86.67 \\
& S2 & 3 & 3.33 \\
Skala perusahaan & Pemerintah & 15 & 16.67 \\
& BUMN & 45 & 50.00 \\
& Swasta & 30 & 33.33 \\
\hline
\end{tabular}

Berdasarkan Tabel 4 dapat diketahui bahwa responden paling banyak adalah laki-laki (63.3\%) dibanding perempuan (36.7\%). Hal ini wajar terjadi dikarenakan pekerjaan konstruksi memang didominasi oleh laki-laki dengan tipe pekerjaan lapangan. Tingkat pendidikan didominasi oleh lulusan DIV/S1 yang mencapai $86.6 \%$, disusul dengan lulusan DIII sebesar 10\% dan S2 3.3\%. Lulusan DIV/S1 merupakan lulusan paling banyak karena sebagian besar perusahaan atau pemerintah membutuhkan lulusan DIV/S1 sebagai tenaga kerja konstruksi. Sedangkan, mereka yang sudah S2 rata-rata bekerja sebagai akademisi. Skala perusahaan responden paling banyak di BUMN diikuti oleh perusahaan swasta dan pemerintah yang dalam hal ini Kementerian Pekerjaan Umum dan Perumahan Rakyat (PUPR).

Pada Tabel 5 diketahui bahwa usia rata-rata dari 90 responden adalah 24 tahun 10 bulan dan lama pengalaman kerja responden adalah 1 tahun 6 bulan. Meskipun tidak ada standar baku terkait berapa kategori usia pekerja fresh graduate, namun perusahaan biasanya mensyaratkan usia 22-27 tahun sebagai kategori fresh graduate ketika membuka informasi lapangan kerja [15]. Sehingga bisa dikatakan usia rata-rata responden pada penelitian ini termasuk dalam kategori fresh graduate. Jika dikorelasikan dengan generasi saat ini, usia tersebut termasuk dalam generasi milenial. 
Tabel 5. Komposisi Responden Berdasarkan Usia dan Masa

\begin{tabular}{ll}
\multicolumn{1}{c}{ Kerja } & \multicolumn{1}{c}{ Waktu } \\
\hline \multicolumn{1}{c}{ Indikator } & 24 tahun 10 bulan \\
Usia & 1 tahun 6 bulan \\
\hline
\end{tabular}

Pandangan responden terhadap indikator kepuasan kinerja menurut perspektif pekerja konstruksi fresh graduate berdasarkan Tabel 1, ditampilkan pada Tabel 6.

Tabel 6. Pandangan Responden terhadap indikator kepuasan kinerja menurut perspektif pekerja konstruksi fresh graduate berdasarkan Tabel 1

\begin{tabular}{ccccc}
\hline $\begin{array}{c}\text { Kode } \\
(1)\end{array}$ & $\begin{array}{c}\text { Penerapan } \\
(2)\end{array}$ & $\begin{array}{c}\text { Tingkat } \\
\text { Kepentingan } \\
(3)\end{array}$ & $\begin{array}{c}\text { Skor } \\
(4)= \\
(2) \times(3)\end{array}$ & $\begin{array}{c}\text { Rank } \\
(5)\end{array}$ \\
\hline A1 & 3.567 & 4.533 & 16.169 & 6 \\
A2 & 4.067 & 4.567 & 18.574 & 1 \\
A3 & 3.800 & 4.500 & 17.100 & 4 \\
A4 & 3.967 & 4.467 & 17.721 & 2 \\
A5 & 3.667 & 3.967 & 14.547 & 13 \\
A6 & 3.600 & 4.300 & 15.480 & 8 \\
A7 & 3.867 & 4.400 & 17.015 & 5 \\
\hline B1 & 3.567 & 3.800 & 13.555 & 14 \\
B2 & 3.433 & 4.333 & 14.875 & 12 \\
B3 & 3.467 & 4.333 & 15.023 & 11 \\
B4 & 3.367 & 4.000 & 13.468 & 15 \\
B5 & 4.100 & 4.300 & 17.630 & 3 \\
B6 & 3.700 & 4.200 & 15.540 & 7 \\
B7 & 3.600 & 4.300 & 15.480 & 8 \\
B8 & 3.633 & 4.200 & 15.259 & 10 \\
\hline
\end{tabular}

Berdasarkan Tabel 6 dapat dilihat bahwa perspektif pekerja konstruksi fresh graduate beraneka ragam terhadap indikator yang diajukan. Sebagai contoh perhitungan, diambil sampel indikator dengan kode A1. Pada Tabel 6, Nilai tingkat penerapan (2) didapat dari hasil rata-rata pendapat responden terhadap indikator pemimpin termotivasi untuk menginspirasi orang dalam mencapai tujuan. Nilai tingkat penerapan 3.567 yang berarti indikator tersebut pada kenyataannya antara kadang-kadang terjadi dan terjadi. Nilai tingkat kepentingan (3) sebesar 4.533 yang berarti indikator tersebut dalam pelaksanaannya masuk kategori antara penting dan sangat penting. Kedua nilai tersebut kemudian dikalikan untuk mendapatkan skor indikator. Hasil perkalian menunjukkan skor indikator ini adalah 16.169, jika dirangking maka akan menduduki peringkat ke-6 dari 15 indikator yang ada. Jika indikator dalam penerapannya sangat sering terjadi dan tingkat kepentingannya sangat tinggi maka skor maksimalnya seharusnya 25 dan jika sebaliknya skor minimalnya adalah 1.

Indikator yang paling banyak dirasakan oleh pekerja konstruksi fresh graduate jika dilihat dari semua indikator kedua aspek, baik aspek kepemimpinan dan pengembangan individu adalah pemimpin harus memiliki pengetahuan kerja yang mendalam (A2). Sedangkan indikator yang paling minim dirasakan adalah materi pelatihan dibakukan (B4). Secara lebih jelas dalam bentuk grafik dapat dilihat pada Gambar 1.

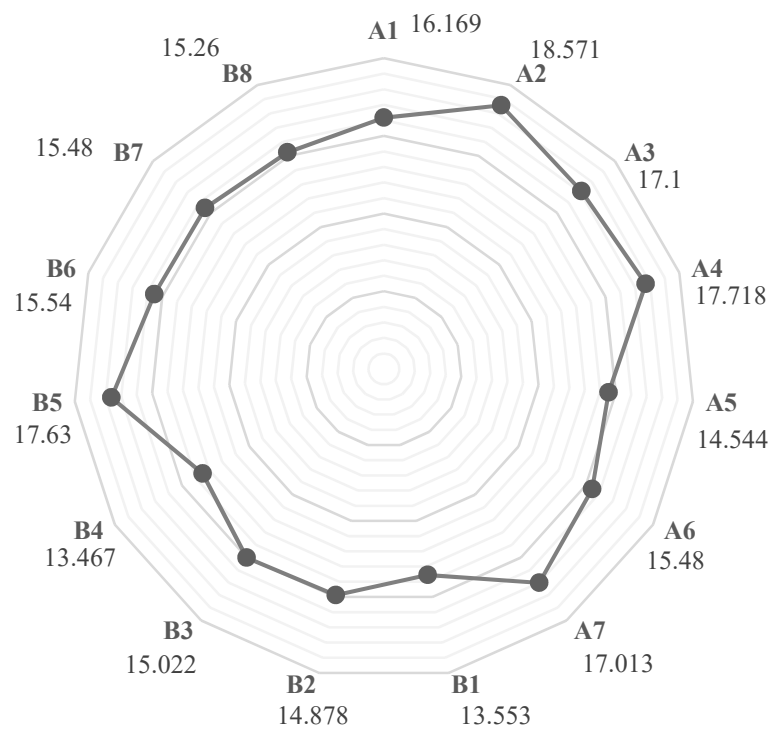

Gambar 1. Grafik Kepuasan Kinerja Pekerja Konstruksi Fresh Graduate

Jika indikator kepemimpinan dan pengembangan individu \& teamwork dipisah dalam rangka memudahkan analisa, maka setiap indikator tersebut dapat dibuat diagram radar chart, yang dapat dilihat pada Gambar 2 (a) untuk Grafik Kepuasan Kinerja Fresh Graduate Aspek Kepemimpinan dan Gambar 2 (b) untuk Grafik Kepuasan Kinerja Fresh Graduate Aspek Pengembangan Individu \& Teamwork.

Berdasarkan Gambar 2 (a) dapat dilihat bahwa A2 atau pemimpin harus memiliki pengetahuan kerja yang mendalam menjadi indikator yang paling tinggi dengan skor 18.574, tingkat penerapan sebesar 4.067 dan tingkat kepentingan sebesar 4.567. Indikator ini menjadi paling utama karena responden merasa selama ini pemimpin telah memiliki pengalaman kerja yang mendalam dengan masa kerja lama dan variasi pekerjaan yang dikerjakan. Pekerja konstruksi fresh graduate merasa puas dengan kinerja pemimpinnya dapat 
dilihat dari adanya indikator tersebut. Indikator ini menjadi yang paling tinggi disebabkan oleh beberapa hal, salah satunya pengaruh knowledge management oleh pemimpin perusahaan atau proyek yang sudah pengalaman. Knowledge management yang baik dapat meningkatkan kinerja SDM dengan tim IT, tim perubahan bisnis, dan tim pemerintahan [16]. Sedangkan indikator yang paling kecil penerapan dan tingkat kepentingannya adalah A5 atau pemimpin akan membutuhkan waktu untuk memahami masalah dan akar penyebab sebelum bertindak. Skornya adalah 14.547, dengan tingkat penerapan 3.667 dan tingkat kepentingan 3.967. Hal ini dapat didasari alasan bahwa selama bekerja responden merasa pemimpin cukup lama dalam memahami masalah dan kemudian mengambil keputusan. Beberapa faktor penyebabnya adalah tingkat risiko, tekanan dari atasan, dan faktor internal pemimpin.

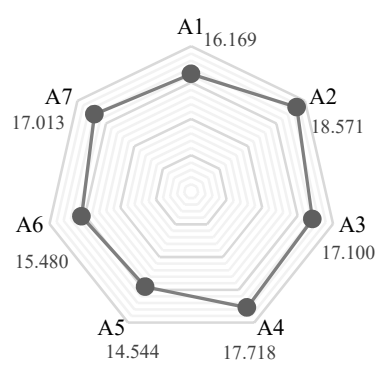

(a)

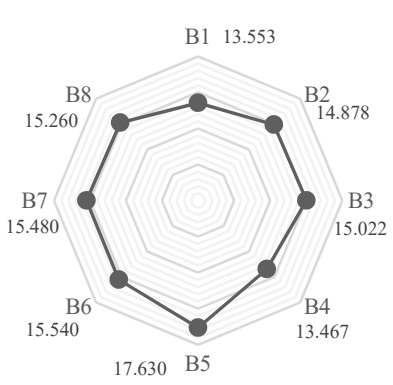

(b)
Gambar 2. (a) Grafik Kepuasan Kinerja Fresh Graduate Aspek Kepemimpinan

(b) Grafik Kepuasan Kinerja Fresh Graduate Aspek Pengembangan Individu \& Teamwork

Gambar 2 (b) menunjukkan grafik kepuasan kinerja berdasarkan aspek pengembangan individu \& teamwork. Indikator dengan skor tertinggi adalah B5 atau pekerja didorong untuk bekerja sama dengan orang lain untuk menyelesaikan seluruh tugas sebesar 17.630 dengan tingkat penerapan 4.100 dan tingkat kepentingan 4.300. Sedangkan indikator dengan skor terendah adalah B4 atau materi pelatihan dibakukan sebesar 13.468 dengan tingkat penerapan 3.367 dan tingkat kepentingan 4.000. B5 menjadi yang paling tinggi karena pada saat ini perusahaan konstruksi mulai mengajak para pekerjanya untuk saling berkolaborasi. Kolaborasi yang dilakukan ini merupakan kolaborasi antar pekerja di satu divisi atau dengan divisi lain, bahkan tidak menutup kemungkinan dengan perusahaan lain. Sehingga para pekerja fresh graduate merasa puas dengan indikator ini. Indikator B4 menjadi yang paling rendah karena responden menilai bahwa banyak materi pelatihan yang hanya mengikuti materi yang telah ada sebelumnya tanpa disesuaikan dengan keadaan saat ini. Penyegaran materi yang dibakukan perlu dilakukan agar menjadi standar yang baik untuk perusahaan.

Penilaian tingkat kepuasan kerja pekerja konstruksi fresh graduate jika dilihat secara keseluruhan ditampilkan dalam Gambar 3. Peta kepuasan kerja pekerja konstruksi fresh graduate ini diadopsi dari konsep manajemen risiko yang melakukan pendekatan terstruktur dalam mengelola ketidakpastian dengan mengukur probability dan severity [17]. Cara memetakan indikator kedalam peta dengan memasukkan nilai penerapan pada sumbu $\mathrm{x}$ dan nilai tingkat kepentingan pada sumbu y, dimana setiap sumbu memiliki skala 1-5. Kemudian, Memasukkan nilai yang tidak bulat atau dalam desimal dari hasil perhitungan masing-masing indikator ke dalam peta dengan cara pendekatan.

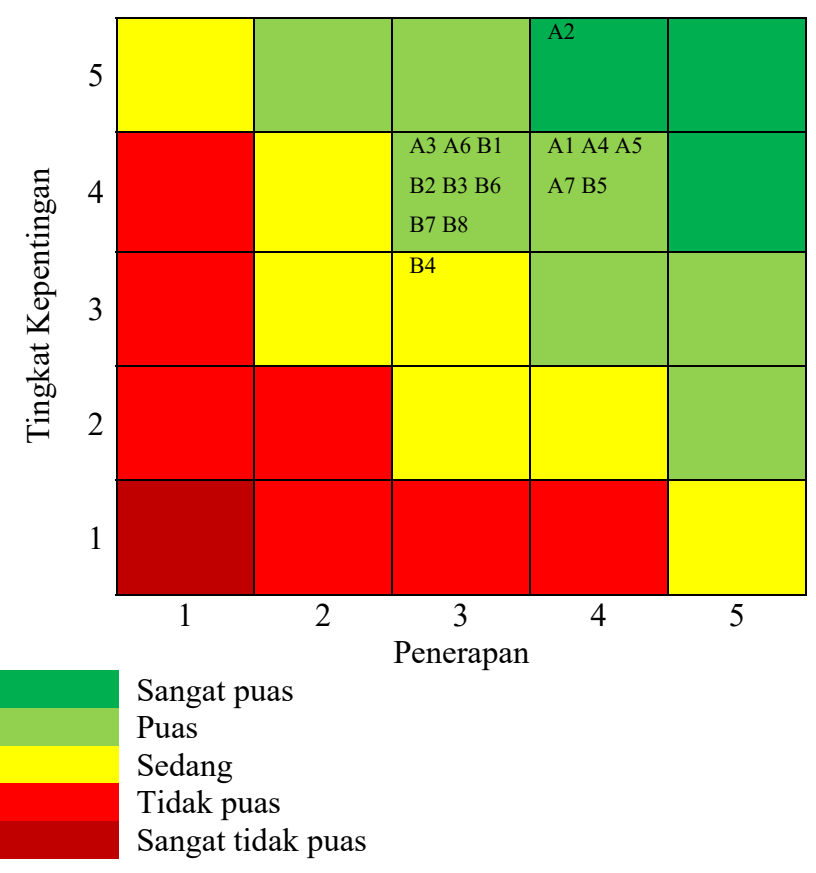

Gambar 3. Peta Kepuasan Kerja Pekerja Konstruksi Fresh Graduate

Berdasarkan Gambar 3, indikator yang masuk kategori sangat puas adalah pemimpin harus memiliki pengetahuan kerja yang mendalam (A2). Materi pelatihan dibakukan (B4) masuk kategori sedang antara puas dan tidak puas. Sedangkan indikator sisanya masuk ketogori puas. Secara keseluruhan hampir semua indikator dikatakan puas menurut perspektif fresh graduate. Peta kepuasan kinerja ini dapat digunakan untuk kajian atau penelitian lainnya, yang dilakukan 
dengan cara memasukkan angka dari dua variabel di sumbu $\mathrm{x}$ (penerapan) dan sumbu y (tingkat kepentingan).

Selain dari pengisian kuesioner yang merujuk pada indikator yang sudah ada, responden juga memberikan masukan dari pengalamannya bekerja sebagai pekerja konstruksi fresh graduate selama ini. Berdasarkan hasil diskusi, aspek kepemimpinan menjadi aspek yang paling banyak memiliki masukan. Masukan Pertama adalah pemimpin yang memberi empati dalam bentuk reward setelah tim berhasil berjuang sampai tujuan. Minimal berupa ucapan terimakasih, makan bersama, olahraga bersama, atau pembagian sisa hasil usaha sesuai peraturan. Tidak lupa sosok pemimpin yang berakhlak mulia, religious, dan toleran juga diharapkan oleh para fresh graduate untuk menjadi pimpinan mereka. Selain itu, Responden juga mengatakan bahwa pemimpin adalah representatif kecil dari perusahaan, sehingga dengan adanya hal tersebut maka responden sebagai fresh graduate dan new employment merasa diperhatikan oleh perusahaan.

Kedua, Pemimpin harus mengikuti perkembangan pasar dan ketersediaan material pasar dalam proses pengadaan. Salah satu yang perlu dicermati adalah kemampuan pemimpin dalam manajemen rantai pasok. Kemampuan ini sangat penting di level perusahaan dalam menunjang suistanable construction [18]. Ketiga, sikap tegas yang merujuk pada bagaimana kemampuan pemimpin mengelola emosi. Usulan indikator ini lebih ke sifat personal dari pemimpin. Oleh karena itu perlu adanya sekolah kepemimpinan yang lebih massif lagi. Keempat, pemimpin harus mampu mengkomunikasikan visi dan misi perusahaan agar pekerja paham dengan jelas sehingga mereka dapat bekerja sesuai arah tujuan yang lebih jelas.

Aspek pengembangan individu dan teamwork memang tidak banyak memberikan masukan tetapi aspek ini cukup penting juga dalam pengaruhnya terhadap kinerja pekerja. Berbagai pelatihan yang tersistem perlu lebih dikembangkan dalam rangka meningkatkan kemampuan dan keterampilan para pekerja. Jenis pelatihan yang tersertifikasi menjadi salah satu hal yang diharapkan. Selain itu model pelatihan jarak jauh (distance learning) berbasis online juga dapat dikembangkan karena waktunya yang lebih fleksibel. Terlebih sasarannya adalah para pekerja konstruksi fresh graduate yang sangat dekat dengan internet dan segala aplikasinya.

\section{Simpulan}

Penelitian ini telah mengkaji bagaimana kepuasan kerja para pekerja konstruksi fresh graduate generasi milenial di Indonesia. Data didapatkan dari 90 responden pekerja baru di perusahaan konstruksi seperti lembaga pemerintah, BUMN, dan swasta sebagai sampel. Indikator kinerja diadopsi dari prinsip lean construction yang dipopulerkan oleh The Toyota Way dengan mengambil dua aspek yaitu kepemimpinan dan pengembangan individu \& teamwork. Aspek kepemimpinan memiliki 7 indikator, sedangkan aspek pengembangan individu \& teamwork memiliki 8 indikator.

Hasil menunjukkan bahwa indikator yang masuk kategori sangat puas yaitu pemimpin harus memiliki pengetahuan kerja yang mendalam. Sedangkan, indikator sebagai kategori sedang yaitu materi pelatihan dibakukan. Selanjutnya, Tiga belas indikator lainnya masuk dalam ketegori puas. Pemisahan grafik dilakukan antara aspek kepemimpinan dan pengembangan individu \& teamwork untuk membantu analisa. Sehingga dapat dikatakan indikator dari prinsip lean construction The Toyota Way dapat digunakan dan diterapkan dalam mengukur kepuasan kinerja di konstruksi.

Hasil penelitian ini perlu dikembangkan lebih mendalam agar dapat dijadikan referensi para pekerja konstruksi fresh graduate generasi milenial. Adopsi dari metode lean construction oleh The Toyota Way dapat dikolaborasikan dengan hasil penelitian untuk kemudian dilakukan penelitian lanjutan. Selain itu dapat juga berkolaborasi dengan metode lain yang berkaitan. Strategi peningkatan kepuasan kinerja perlu dikaji lebih dalam untuk mengetahui metode yang perlu dilakukan oleh perusahaan maupun pekerja ketika menghadapi masalah sesuai indikator dalam The Toyota Way tersebut. Selain itu pandangan kepuasan kinerja dari sudut pandang pengguna atau perusahaan juga perlu dikaji agar mendapatkan keseimbangan pandangan terkait kepuasan kerja pekerja konstruksi fresh graduate generasi milenial.

\section{Daftar Pustaka}

[1] B. P. Statistik, Konstruksi dalam Angka 2017, 2017.

[2] M. A. Wibowo, N. U. Handayani, A. Nurdiana, M. N. Sholeh, and G. S. Pamungkas, "Mapping of information and identification of construction waste at project life cycle," in AIP Conference Proceedings, 2018, p. 020049.

[3] I. Djastuti, "Pengaruh Karakteristik Pekerjaan Terhadap Komitmen Organisasi Karyawan Tingkat Managerial Perusahaan Jasa Konstruksi di Jawa Tengah," Jurnal Bisnis dan Akuntansi, vol. 13, pp. 119, 2011.

[4] N. Van Tam, N. L. Huong, and N. B. Ngoc, "Factors affecting labour productivity of construction worker on construction site: A case of Hanoi," Journal of Science and Technology in Civil Engineering (STCE)NUCE, vol. 12, pp. 127-138, 2018.

[5] H. Aziz and B. Hidayat, "Motivasi Pekerja Pada Proyek Konstruksi di Kota Padang," Jurnal Rekayasa Sipil (JRS-Unand), vol. 13, pp. 29-42, 2017.

[6] R. Ruvendi, "Imbalan dan gaya kepemimpinan pengaruhnya terhadap kepuasan kerja karyawan di 
Balai Besar Industri Hasil Pertanian Bogor," Jurnal ilmiah binaniaga, vol. 1, pp. 17-26, 2018.

[7] I. W. N. Susanta, M. Nadiasa, and I. B. R. Adnyana, "Pengaruh Kompensasi dan Kepemimpinan Terhadap Kinerja Karyawan Pada Jasa konstruksi di Denpasar," Jurnal Ilmiah Elektronik Infrastruktur Teknik Sipil, vol. 2, pp. 1-8, 2013.

[8] J. B. Balda and F. Mora, "Adapting leadership theory and practice for the networked, millennial generation," Journal of Leadership Studies, vol. 5, pp. 13-24, 2011.

[9] C. M. Morris, "A quantitative study about job satisfaction perception among four generational cohorts in today's workforce," Capella University, 2011.

[10] D. Gursoy, T. A. Maier, and C. G. Chi, "Generational differences: An examination of work values and generational gaps in the hospitality workforce," International Journal of Hospitality Management, vol. 27, pp. 448-458, 2008.

[11] B. Suryadi, "Generasi y: karakteristik, masalah, dan peran konselor," 2015.

[12] H. C. Diartho, "Penyerapan Tenaga Kerja Sektor Konstruksi di Indonesia (Studi pada 6 Provinsi di Jawa)," Media Trend, vol. 13, pp. 241-254, 2018.

[13] L. Alarcón, Lean construction: CRC Press, 2014.

[14] S. Gao and S. P. Low, Lean Construction Management: Springer, 2014.

[15] J. R. Abel and R. Deitz, "Underemployment in the early careers of college graduates following the Great Recession," National Bureau of Economic Research2016.

[16] B. H. Reich, A. Gemino, and C. Sauer, "How knowledge management impacts performance in projects: An empirical study," International Journal of Project Management, vol. 32, pp. 590-602, 2014.

[17] A. J. McNeil, R. Frey, and P. Embrechts, Quantitative Risk Management: Concepts, Techniques and Toolsrevised edition: Princeton university press, 2015.

[18] M. A. Wibowo, M. N. Sholeh, and H. S. Adji, "Supply chain management strategy for recycled materials to support sustainable construction," Procedia engineering, vol. 171, pp. 185-190, 2017. 
